\title{
A TOMADA DE CONSCIÊNCIA ACERCA DE ASPECTOS QUE ENVOLVEM A PRODUÇÃO DE TEXTOS ESCRITOS: UM ESTUDO INTERVENCIONISTA
}

\begin{abstract}
Clarice Vaz Peres Alves é professora da Faculdade Anhanguera Educacional - Pelotas, RS. Atua no curso de Direito. É Mestre em Letras (2002) pela Universidade Católica de Pelotas e Doutora em Educação (2013) pela Universidade Federal de Pelotas. Integrante do grupo de pesquisa Educação e Psicologia Histórico-Cultural, coordenado pela prof ${ }^{\mathrm{a}}$. Dr ${ }^{\mathrm{a}}$. Magda Damiani. Email: claricevpalves@gmail.com

Magda Floriana Damiani - é professora da Faculdade de Educação da Universidade Federal de Pelotas, atuando no Programa de Pós-graduação em Educação, na Linha de Pesquisa "Cultura Escrita, Linguagens e Aprendizagem” e no Curso de Pedagogia. É Mestre em Psicologia Educacional (1983) e Doutora em Educação (1998), ambos pela Universidade de Londres/Inglaterra, tendo realizado estágio Pós-doutoral na Universidade de Siegen/Alemanha. É bolsista de produtividade em pesquisa do CNPq.

Email: flodamiani@gmail.com
\end{abstract}

\section{Resumo}

O presente artigo tem como objetivo discorrer sobre o desenvolvimento da tomada de consciência acerca de aspectos que envolvem a produção de textos escritos no contexto acadêmico. As reflexões apresentadas estão amparadas pelas ideias de L. S. Vygotski e de M. Bakhtin. Os achados do estudo ratificam as ideias desses dois autores sobre a importância das interações sociais, mediadas pela palavra, para o desenvolvimento da tomada de consciência.

\begin{abstract}
This article aims to discuss the development of awareness about issues involved in the production of written texts in the academic context. The thoughts presented here are supported by the ideas of L.S. Vygotsky and M. Bakhtin. The findings of the study confirm the ideas of these two authors on the importance of social interactions, mediated by the word, to the development of awareness.
\end{abstract}

\section{1) Introdução}

O presente artigo tem como objetivo discorrer sobre o desenvolvimento da tomada de consciência acerca de aspectos que envolvem a produção de textos escritos. As reflexões aqui apresentadas estão amparadas pelas ideias de L. S. Vygotski e de M. Bakhtin. Provocar um encontro entre esses dois autores é relevante, pois entendemos que ambos oferecem aporte teórico extremamente importante para este estudo.

Entre vários outros temas, Vygotski (1995; 1997; 2009) dedica-se a estudar a consciência e o desenvolvimento psicológico humano, ressaltando o papel da linguagem como sistema simbólico responsável pela formação do pensamento. Bakhtin (2006), igualmente, destaca a linguagem como organizadora da atividade mental e como basilar na constituição da consciência e do sujeito. Com base nos escritos desses autores, podemos entender a linguagem a partir de uma perspectiva dialógica, resultante das interações estabelecidas entre os seres humanos que compartilham uma dada cultura. Assim, a concepção de linguagem que norteou este estudo é a que a aborda como instrumento de interação humana; como lugar de interlocução; como ação que constitui e modifica os processos psíquicos do sujeito; como elemento de mediação entre o ser humano e o mundo circundante. A linguagem interpretada como interação verbal entre os membros de uma determinada cultura corresponde à noção de ser humano como alguém que interage por meio das relações interpessoais, mediadas pela linguagem. Dessa forma, compreendemos que o sujeito deve desempenhar uma função interativa na apropriação de seu conhecimento, constituindo-se e contribuindo com a constituição do outro por meio da linguagem e da interação. Portanto, para nós, um sujeito interativo é aquele que realiza um movimento dialético na construção de seu desenvolvimento psíquico e intelectual.

A partir das concepções de linguagem e sujeito alicerçadas na interação social, o texto escrito, nesta investigação, é entendido como processo. Isso significa que o texto 
se constitui gradativamente, mediante uma relação interativa entre escritor, texto e leitor.

O estudo, aqui apresentado, é um recorte de uma tese de doutoramento. A investigação que realizamos não foi de natureza diagnóstica, mas de caráter intervencionista, que objetivou desenvolver a tomada de consciência e a capacidade de controle sobre a prática de textos escritos por acadêmicos, pertencentes a um curso de licenciatura.

Defendemos que o desenvolvimento da tomada de consciência e da capacidade de controle acerca da escrita pode ser maximizado por meio de atividades coletivas, mediadas pela linguagem. Para Vygotski (2009), a linguagem é uma das ferramentas do pensamento. É o sistema simbólico responsável pelo desenvolvimento do ser humano. $\mathrm{O}$ autor defende que é por meio de um movimento dialético do social para o individual, mediado pela linguagem, que o sujeito se constitui, internaliza conhecimentos, papéis e funções sociais, formando a própria consciência. Assim, compreendemos que o papel do educador, no aprimoramento da linguagem escrita de seus educandos, é de vital importância, já que, por meio dele, uma relação dialógica entre escritor e texto pode e deve ser provocada, situação essencial ao desenvolvimento da tomada de consciência sobre os aspectos discursivos e linguísticos do texto e da capacidade de controle sobre tais aspectos. Julgamos esse movimento essencial aos estudantes para que desenvolvam uma escrita compreensiva, reflexiva e responsiva, de acordo com as palavras de Bakhtin (2006).

Após esta breve introdução, apresentamos algumas reflexões teóricas que orientam as análises aqui discutidas. A seguir, descrevemos o percurso metodológico, que é constituído pelo método da intervenção pedagógica, pelo método de avaliação da intervenção e pelos achados relativos à intervenção. E, por fim, apresentamos algumas reflexões sobre o estudo que realizamos.

\section{2) Breves reflexões teóricas sobre a gênese e o desenvolvimento da consciência na interpretação de L. S. Vygotski e de M. Bakhtin}

Para Vygotski (1997), o ser humano não se constitui através de fenômenos internos, nem se reduz a uma soma de reflexos oriundos do meio, mas se origina mediante a relação que estabelece com o meio, mediada pela linguagem. Para o autor, a linguagem não é apenas um instrumento comunicativo, mas uma condição sine qua non do desenvolvimento humano, argumentando que "é na linguagem que se encontra precisamente a fonte do comportamento social e da consciência" (VYGOTSKI, 1997, p.57).

A palavra, explica o autor, constitui-se em um reflexo reversível na formação do comportamento humano e da consciência, chamando atenção para um grupo especial de reflexos, os que resultam dos excitantes sociais, isto é, os que emanam das pessoas. Vygotski (1997) explica que os reflexos reversíveis são a base do comportamento social, pois "tenho consciência de mim na medida em que para mim sou o outro" e que "a vertente individual se constrói como derivada e secundária sobre a base do social" (VYGOTSKI, 1997, p.57). O autor destaca que a construção da consciência ocorre por meio de uma relação estabelecida entre o eu e o outro, mediada pela linguagem, ratificando a origem social da consciência. Ressalta também a função social do signo, 
afirmando que ele modifica as relações entre indivíduos e ratifica a importância da mediação, desempenhada pelos instrumentos físicos e pelos signos para o desenvolvimento da consciência. Portanto, de acordo com o pensamento vygotskiano, a origem e o desenvolvimento da consciência estão fundamentados nas relacionais sociais, efetivadas por meio da linguagem.

Com base na análise histórica e genérica que realizamos sobre as ideias de Vygotski (1997) acerca da consciência, podemos concluir que, para o autor, a consciência emerge na coletividade, por meio da linguagem e das relações que os indivíduos estabelecem com o contexto do qual fazem parte. Ela surge e se desenvolve de fora para dentro; do social para o individual. É o resultado das relações estabelecidas entre os seres humanos em uma dada cultura.

Vale ressaltar que o autor indica em seus estudos que há diferença entre consciência e tomada de consciência, explicando que

a tomada de consciência de nossos atos e estados devem ser interpretados como sistema de transmissores de uns reflexos a outros que funcionam corretamente - em cada momento consciente. Quanto maior for o ajuste com que qualquer reflexo interno em qualidade de excitante provoque uma nova série de reflexos procedentes de outros sistemas e se transmita a outros sistemas, mais capazes seremos de nos darmos conta de nossas sensações, comunicá-las aos demais e vivê-las (senti-las, fixá-las nas palavras etc). A lei geral do desenvolvimento consiste em que a tomada de consciência e a assimilação não são inerentes apenas à fase superior de desenvolvimento de alguma função. Elas surgem mais tarde. Devem ser necessariamente antecedidas do estágio de desenvolvimento não conscientizado e não arbitrário desse tipo de atividade consciente (VYGOTSKI, 1997, p.9).

As palavras de Vygotski explicam que há diferença entre consciência e tomada de consciência e que ambos os processos mentais são desenvolvidos a partir de elementos externos. Portanto, de acordo com nossa compreensão, a tomada de consciência é um estágio anterior e necessário à constituição da consciência.

Para Bakhtin (2006), o único conceito de consciência aceitável é o de natureza sociológica. Ele explica que a consciência não provém diretamente da natureza, como é interpretada pelo materialismo mecanicista e pela psicologia contemporânea. Defende que a consciência individual só pode ser compreendida a partir do meio ideológico e social, destacando a importância dos signos no processo de formação e interpretação dessa consciência. De acordo com o autor, "[a] consciência adquire forma e existência nos signos criados por um grupo organizado no curso de relações sociais. Os signos são o alimento da consciência individual, a matéria de seu desenvolvimento [...]" (BAKHTIN, 2006, p.36). Assim, argumenta que a imagem, o gesto significante, a palavra são considerados o "abrigo" da consciência. A palavra, segundo Bakhtin, é o principal instrumento de formação da consciência individual. Esclarece que não seria possível o desenvolvimento da consciência se esta "não dispusesse de um material flexível, veiculável pelo corpo. E a palavra constitui exatamente esse tipo de material" (BAKHTIN, 2006, p.37). Para o autor, a palavra pode ser empregada como signo interior, isto é, como signo sem expressão externa, constituindo o elemento semiótico da 
vida interior da consciência e afirma "sua presença obrigatória [da palavra], como fenômeno acompanhante, em todo ato consciente" (BAKHTIN, 2006, p.39).

$\mathrm{O}$ autor explicou que o signo é um produto ideológico que pertence a

uma realidade (natural ou social) como todo corpo físico, instrumento de produção ou produto de consumo; mas, ao contrário destes, ele também reflete e refrata uma outra realidade, que lhe é exterior. Tudo que é ideológico possui um significado e remete a algo situado fora de si mesmo. Em outros termos, tudo que é ideológico é um signo. Sem signos não existe ideologia. [...] E toda imagem artístico-simbólica ocasionada por um objeto físico particular já é um produto ideológico. O mesmo se dá com um instrumento de produção. Em si mesmo, o instrumento não possui um sentido preciso, mas apenas uma função: desempenhar este ou aquele papel na produção. [...] Todavia, um instrumento pode ser convertido em signo ideológico: é o caso, por exemplo, da foice e do martelo como emblema da União Soviética. [...] o instrumento, enquanto tal, não se torna signo e o signo, enquanto tal, não se torna instrumento de produção. [...]. Ali onde o signo se encontra, encontra-se também o ideológico. Tudo o que é ideológico possui valor semiótico. Cada signo ideológico é não apenas um reflexo, uma sombra da realidade, mas também um fragmento material dessa realidade. Todo fenômeno que funciona como signo ideológico tem uma encarnação material, seja como som, como massa física, como cor, como movimento de um corpo ou como outra coisa qualquer. [...] Um signo é um fenômeno do mundo exterior (BAKHTIN, 2006, p.31-33, grifos do autor).

Assim, de acordo com o exposto, podemos concluir que os signos são revestidos por ideologias e constituídos por intermédio das relações sociais. Entretanto, Bakhtin (2006) esclarece que não basta colocar frente a frente dois indivíduos quaisquer para que os signos se constituam. É necessário que esses indivíduos estejam organizados socialmente, que formem um grupo, somente dessa forma, o sistema de signos poderá ser constituído.

Com base no que foi mencionado sobre o pensamento bakhtiniano sobre a gênese e o desenvolvimento da consciência, concluímos que Bakhtin, assim como Vygotski, entende a consciência como uma atividade mental, que não é inata no ser humano, nem se desenvolve por meio de leis biológicas. Para ele, a constituição e o desenvolvimento da consciência são dependentes das relações signícas e sociais, formadas entre os indivíduos inseridos em determinado meio social.

Partindo da ideia desses dois autores, compreendemos a consciência como um processo mental, oriundo das relações sociais e que possibilita ao ser humano refletir, analisar, planejar, interpretar e decidir suas próprias ações. Portanto, as relações sociais que o indivíduo estabelece com o contexto no qual está inserido são determinantes do conteúdo de sua consciência, podendo esta ser mais ou menos desenvolvida.

\section{3) Percurso Metodológico}

De acordo com as reflexões empreendidas pelo nosso grupo de pesquisa ${ }^{1}$,

\footnotetext{
${ }^{1}$ Nosso grupo de pesquisa é constituído por doutorandos e mestrandos. A delimitação de sentido do termo 
podemos definir uma pesquisa do tipo intervenção como aquela que envolve interferências realizadas em processos educacionais, com base em um dado referencial teórico, tendo o propósito de produzir avanços em tais processos, avanços esses avaliados ao término das ações interventivas. Esse tipo de pesquisa foi denominado como pesquisa do tipo intervenção pedagógica, pois envolve intervenções para maximizar os processos de aprendizagem de determinados sujeitos (DAMIANI et al., 2013; DAMIANI, 2012). Assim, o roteiro proposto por Damiani et al. (2013) para elaboração de relatórios de pesquisa-intervenção pedagógica inclui a descrição dos seguintes elementos: o método da intervenção, que descreve, de maneira detalhada, a intervenção em si, ou seja, a proposta pedagógica implementada, e o método de avaliação da intervenção, que descreve os instrumentos utilizados para avaliar os efeitos da intervenção.

\section{1) Método da intervenção pedagógica}

Implementamos a intervenção por meio de uma disciplina optativa, denominada Produção de Textos, com estudantes de diferentes semestres do curso de Pedagogia de uma universidade pública. A escolha pelo referido curso e por essa instituição deveu-se ao fato de a orientadora deste estudo atuar nessa instituição e nesse curso.

O estudo foi desenvolvido no primeiro semestre de 2012, no período de 16/3/2012 a 22/6/2012, totalizando treze encontros. Os encontros eram alternados por atividades de escrita, revisão e reescrita de textos. O gênero textual trabalhado foi o resumo. Optamos por esse gênero em virtude de ele assumir papel de destaque na inserção dos estudantes em práticas discursivas presentes no domínio acadêmicocientífico, além de pertencer à composição de outros gêneros como, por exemplo, a resenha. Considerando os diferentes tipos de resumo existentes, adotamos a concepção de resumo como resultado de um processo de retextualização de outros gêneros, ou seja, a transformação de um texto em outro.

A turma em que realizamos a intervenção pedagógica era composta por dezessete estudantes, sendo somente um do sexo masculino. Destes, para efeitos de análise, foram considerados apenas cinco, cuja escolha não foi aleatória. No terceiro encontro realizado com o grupo, após explicarmos o objetivo da pesquisa que intencionávamos realizar, questionamos quem estaria disposto a dela participar. Cinco foram os voluntários ${ }^{2}$ : Hortência ( $2^{\circ}$ semestre); Violeta ( $3^{\circ}$ semestre); Magnólia $\left(4^{\circ}\right.$ semestre); Margarida ( $5^{\circ}$ semestre) e Rosa ( $5^{\circ}$ semestre). Esse foi o critério que utilizamos para a seleção dos participantes, ou seja, a disponibilidade deles em contribuir com nossa investigação. Vale ressaltar que o grupo das cinco acadêmicas apresentava características muito semelhantes as dos alunos que participaram de uma pesquisa realizado por Damiani et al. (2011) e de um estudo preliminar que

intervenção para denominar o tipo de pesquisa que predomina em nosso grupo foi iniciada, efetivamente, a partir do evento denominado VIII Seminário de Pesquisa Qualitativa, ocorrido no ano de 2009 na Faculdade de Educação da Universidade Federal de Pelotas.

2 Com objetivo de preservar a identidade dos sujeitos, os nomes aqui apresentados são fictícios. Os cinco estudantes são do sexo feminino. Portanto, doravante, vamos empregar esse gênero ao fazermos menção às acadêmicas. 
desenvolvemos no primeiro e no segundo semestres de 2011, ambos implementados no curso de Pedagogia da mesma instituição em que realizamos o presente estudo. Portanto, parece-nos que esse grupo, embora fosse constituído por cinco estudantes, podia ser considerado como uma amostra representativa dos acadêmicos do curso de Pedagogia dessa instituição.

Para efeitos de análise, aplicamos quatro instrumentos: um questionário e uma entrevista semiestruturada no início do semestre; outro questionário ao final do semestre e outra entrevista semiestruturada no início do semestre de 2013.

Objetivando conhecer um pouco das características dos sujeitos participantes deste estudo, aplicamos um questionário no primeiro encontro realizado no semestre. $\mathrm{O}$ questionário era constituído por perguntas relativas às experiências de produção de texto construídas pelas estudantes ao longo de seu processo de escolarização básica. Também investigava se as acadêmicas costumavam revisar e reescrever seus escritos. O questionário nos possibilitou uma melhor compreensão da postura que adotavam em relação aos seus procedimentos de escrita.

Quanto às experiências de escrita, uma disse não lembrar (Hortência); quatro revelaram que raramente produziam textos nesse período de escolarização e, quando o faziam, o retorno sobre esses textos era dado apenas por meio de notas ou mediante algumas correções neles assinaladas. De acordo com as acadêmicas, os textos retornados, dificilmente, continham sugestões para sua melhoria. Todas expressaram que tinham o hábito de revisar seus escritos e que essa revisão era, normalmente, paralela ao momento em que estavam redigindo seus textos. Hortência e Violeta externaram que costumavam revisar parágrafo por parágrafo, substituindo as palavras repetidas e as menos adequadas; Magnólia revelou que costumava escrever e passar a limpo e, nesse momento, fazia a correção, observando se o texto estava claro e coerente, se não estava muito repetitivo e se havia erros ortográficos. Margarida relatou que observava a gramática, a concordância das frases e o desenvolvimento das ideias. E, por fim, Rosa exteriorizou que, após escrever seus textos, revisava os erros ortográficos e observava se seus escritos estavam coerentes.

No encontro posterior à aplicação do questionário, realizamos uma entrevista semiestruturada com as alunas voluntárias. Esclarecemos a elas que suas verbalizações seriam gravadas e, posteriormente, transcritas para efeitos de análise, o que foi permitido e autorizado por elas.

As perguntas que nortearam a entrevista foram as seguintes: como te vês hoje como aluna escritora? Como conduzes a escrita de teus textos? Costumas reler o que tu escreves? Com que propósito? E a revisão, tens por hábito realizá-la? Como procedes? Em que momento da tua escrita? Ao terminar o texto, fazes uma nova leitura dele? As entrevistas tiveram duração média de 15 a 20 minutos. Estas foram gravadas, transcritas por nós e, posteriormente, lidas para cada uma das participantes. Esse procedimento foi adotado também na realização das entrevistas realizadas no início de 2013.

No último encontro do semestre, aplicamos novamente um questionário, que nos permitiu avaliar a intervenção pedagógica que realizamos. Esse questionário era composto por perguntas que possibilitavam às estudantes refletirem sobre seu desempenho na produção de textos escritos, após participarem da intervenção pedagógica.

Quanto às entrevistas pós-intervenção, essas foram realizadas somente no início do primeiro semestre de 2013, pela seguinte razão: havia sido decretada uma greve dos servidores federais, portanto, as acadêmicas não estavam frequentando a 
universidade. De qualquer forma, consideramos interessante que houvesse um intervalo de tempo entre o término da intervenção e as entrevistas, pois pensamos que as respostas produzidas pelas acadêmicas poderiam enfocar efeitos mais significativos da intervenção, que não foram esquecidos com o passar do tempo, o que se confirmou nas entrevistas.

As perguntas que nortearam a entrevista pós-intervenção foram, praticamente, as mesmas realizadas na primeira entrevista. Somente uma pergunta foi modificada: "Como te vês como aluna escritora após participares da disciplina de produção de textos?"; e outra acrescentada: "Que aprendizagens foram realizadas durante a disciplina de produção de textos?" As entrevistas foram realizadas, individualmente, em uma sala, na instituição à qual pertenciam.

Poupart (2008), ao orientar os procedimentos necessários a uma entrevista, sugere que essa seja realizada na casa do entrevistado, em seu local de trabalho, ou em espaços semipúblicos, a fim de que sua rotina de vida não seja alterada, porque, caso haja interferências, a qualidade da entrevista pode ficar comprometida. Assim, seguindo as orientações desse autor, esperamos pelo retorno das atividades acadêmicas, ao final da greve, que ocorreu em março de 2013, para realizarmos as entrevistas com as cinco estudantes. As entrevistas foram realizadas individualmente e tiveram duração entre 20 e 30 minutos e não foram feitas todas no mesmo dia, em virtude da disponibilidade de cada estudante. Combinávamos com cada uma delas o horário que julgavam mais adequado, a fim de não interferirmos em suas rotinas. Também, como na primeira entrevista, explicamos-lhes que suas verbalizações seriam gravadas e transcritas por nós para efeitos de análise, o que foi aceito por elas.

\section{2) Método de avaliação da intervenção}

Nesta parte, apresentamos os instrumentos que nos permitiram avaliar a intervenção. São eles: questionário e entrevista semiestruturada.

Aguiar e Ozella (2006) defendem a validade dos questionários como instrumento de coleta de dados, principalmente quando aprofundados por meio de entrevistas. Entendemos, pois, que o questionário foi importante para a avaliação da intervenção porque, ao ser triangulado com os outros dados coletados, proporcionou maior confiabilidade aos achados da investigação.

Quanto à entrevista semiestruturada (SZYMANSKY, 2004, p. 86), entendemos que é um recurso indispensável "não somente como método para apreender a experiência do outro, mas, igualmente, como instrumento que permite elucidar suas condutas, na medida em que estas só podem ser interpretadas, considerando-se a perspectiva dos atores [...]" (POUPART, 2008, p. 17). O autor argumenta que, no processo de coleta de dados, há várias vantagens em aplicarmos entrevistas, a saber: estar baseada na realidade do entrevistado, como forma de enriquecer o material de análise e o conteúdo da pesquisa; proporcionar maior grau de liberdade do entrevistado; possibilitar uma melhor exposição da experiência do entrevistado. Com base nas ideias do autor, compreendemos que a entrevista semiestruturada atendeu às necessidades desta pesquisa.

Para avaliarmos os dados coletados nas entrevistas e nos questionários apoiamo-nos na análise textual discursiva proposta por Moraes (2003). 


\section{3) Achados Relativos aos Efeitos da Intervenção}

Em virtude da limitação de espaço, neste artigo, vamos discutir somente a primeira parte da avaliação da intervenção, que é constituída pela análise das mudanças observadas nos sujeitos que dela participaram. Essas mudanças foram identificadas mediante a análise dos diferentes instrumentos de coleta de dados, conforme já mencionados. Esses instrumentos sofreram intenso processo de triangulação (VIANNA, 2007) e, posteriormente, foram interpretados a partir do referencial teórico que embasou a intervenção pedagógica que realizamos.

A categoria que vamos discutir a seguir - A tomada de consciência acerca de aspectos que envolvem a produção de textos escritos - é uma categoria a priori e que nos possibilitou avaliar os efeitos da intervenção. Buscamos identificar, nas reflexões escritas e orais realizadas pelas acadêmicas, elementos que revelassem a tomada de consciência sobre aspectos relativos à redação de textos escritos.

Essa categoria foi analisada, tomando como base as respostas apresentadas pelas estudantes no segundo questionário e nas falas oriundas das entrevistas semiestruturadas.

Iniciamos a análise dessa categoria, apresentando algumas falas, originárias das entrevistas realizadas após a intervenção pedagógica. A pergunta que serviu de base para os excertos discutidos abaixo foi a seguinte: Como te vês como aluna-escritora depois da nossa disciplina?

Eu presto mais atenção nos parágrafos, hoje, nas repetições de, de palavras. Eu ainda tenho muita dificuldade de fazer conexão, de coesão, de trazer aquele assunto lá de cima e colocar ali. Eu achava que eu falava muito bem; ia lá e buscava o assunto e hoje vejo que não [...]. Eu faço [os parágrafos] e os assuntos vão ficando; eles não buscam a ideia principal. Essas coisas eu já me dou conta. Essas coisas eu não via. Parágrafo, parágrafo pra mim podia ter até dez linhas, quer dizer, a frase; eu ia indo assim, sabe? É uma coisa que eu presto atenção hoje (VIOLETA - Entrevista pósintervenção, grifos nossos).

Com base nas verbalizações de Violeta, podemos inferir que desenvolveu a tomada de consciência acerca de alguns problemas que sua escrita apresentava, além da tomada de consciência sobre as demandas envolvidas na produção de um texto escrito. A aluna relata que, depois da disciplina, passou a perceber algumas de suas dificuldades em relação à redação de textos, embora ainda apresente limitações para escrever. O fato de ter consciência de suas dificuldades em relação à produção de um texto pode ser interpretado como primeiro passo para a busca de solução de tais dificuldades. Defendemos que a tomada de consciência tanto do que exige a produção de um texto, quanto das dificuldades que se tem com relação a esse processo, é condição essencial para a melhoria da escrita, já que, sem perceber o problema, não é possível buscar uma solução para ele. No entanto, o fato de Violeta tomar consciência da ausência de qualidade em seus textos e dos problemas que apresentam, não significa que irá, necessariamente, desenvolver a capacidade de controle sobre tais problemas, pois, como argumentou Vygotski (1997), ter consciência da tarefa não significa saber resolvê-la. O 
autor explica que, quando tomamos consciência, ou seja, quando nos damos conta de algo como, por exemplo, de uma situação que nos desagrada ou de uma dificuldade cognitiva, a probabilidade de buscar uma alternativa para resolver tal situação ou dificuldade aumenta.

O depoimento de Margarida também expressa o aparecimento da tomada de consciência sobre as demandas implicadas na tarefa de escrever. A estudante expressou que, ao participar da intervenção passou a

ter mais atenção mais atenção na hora da escrita, por exemplo, quando a gente vai escrever um texto né? de repente, a gente escreve, aí tá pronto, terminei, imprimi, deu, menos um. E aí conforme eu fui desenvolvendo a disciplina fui percebendo isso, a importância da gente ler de novo, da gente, como eu posso dizer, da gente fazer anotações, deixar o texto de canto, deixar um pouquinho guardado aquele texto, depois retomar pra gente verificar as ideias, né? Eu continuo escrevendo, mas agora, digamos, com um olhar mais atento pra minha escrita, com aquela preocupação, eu vou ver essa frase de novo pra ver se não tá repetida; agora quem sabe eu substituo por outra, por esse início. É, é foi isso que a disciplina despertou em mim: o cuidado de cuidar o jeito que eu vou escrever (MARGARIDA - Entrevista pósintervenção, grifos nossos).

A fala de Margarida, diferentemente da de Violeta, não demonstra, explicitamente, a tomada de consciência sobre seus próprios problemas de escrita, mas revela uma tomada de consciência sobre a redação de texto como processo e não como produto. Ao dizer que percebe a importância de ler novamente o que escreve, de deixar o texto "guardado" e retomá-lo mais tarde, de ter o "cuidado de cuidar o jeito" que vai escrever, está explicitando que seu olhar sobre a produção de um texto não é o mesmo que tinha antes de participar da intervenção. Quando aponta as ações necessárias para a produção de um texto, como revisão posterior e cuidado, parece estar dizendo, implicitamente, que essas ações são necessárias, para a redação de um texto coeso e coerente.

É possível apreender, nas palavras de Margarida, alguns indicadores do modo como, enquanto acadêmica, percebia o trabalho com as atividades de escrita de textos que eram solicitadas a ela, no decorrer de sua formação como futura professora. A estudante, ao expressar "a gente escreve, aí tá pronto, terminei, imprimiu, deu, menos um", revela que sua escrita era, como consideram Kramer e Oswald (2002, p.13), uma "escrita sem linguagem", sem autoria, sem interlocução. Parece-nos que, para ela, a redação de um texto era uma atividade mecânica, que não envolvia reflexão, análise, revisão e releitura. A acadêmica, anteriormente, exteriorizou uma concepção de texto como produto, como resultado de um único momento de expressão de suas ideias. Suas palavras sugerem que a redação dos textos que lhe era solicitada no contexto acadêmico não tinha, para ela, uma função social, enfim, não era compreendida como constitutiva de sua formação. A estudante deu-nos a impressão de que escrevia sem saber para quê; sem entender o objetivo pelo qual deveria redigir os textos que lhe eram solicitados. A esse respeito, as palavras de Street (2010), ao comentar que é pouco provável que os alunos da graduação perguntem a razão de escrever determinado texto, explicam o comportamento de Margarida. O autor comenta que, em vez de se esperar que eles 
pensem sobre o objetivo de suas escritas, "espera-se que simplesmente 'digam o que sabem' sobre determinada área para demonstrar o conhecimento adquirido" (STREET, 2010, p.554).

Vygotski (1998), ao fazer referência às implicações práticas da linguagem escrita, defende que o ensino deve ser organizado de forma que a leitura e a escrita sejam compreendidas como necessárias ao sujeito: "a escrita deve ser relevante à vida", pois só assim "poderemos estar certos de que ela se desenvolverá não como hábito de mão e dedos, mas como uma forma nova e complexa de linguagem" (VYGOTSKI, 1998, p. 156). Portanto, parece-nos que as atividades de produção de textos solicitadas à Margarida durante sua formação representaram, até o momento da intervenção, apenas um "hábito de mãos e dedos".

Margarida, questionada sobre o hábito de revisar seus escritos, antes de participar da intervenção, verbalizou o seguinte:

\begin{abstract}
Não, eu fazia muito pouco [a revisão]. Eu começava a escrever um texto e, se eu não terminava aquele texto, quando eu ia terminar o texto sim, eu relia para conseguir concluir, mas não para revisar o texto. No caso, se eu terminasse o texto numa tarde, eu terminava, ponto, imprimi e tá pronto, terminou o trabalho. $E$ aí, não costumava a fazer várias revisões. Agora eu faço sim. [...] Às vezes, eu termino o trabalho, mas não imprimo deixo o trabalho no computador e aí quando vou imprimir, eu vou e dou uma olhadinha pra ver se está tudo certo de novo, se não precisa trocar alguma coisa, mas não tinha esse costume não. [...] quando gente deixa descansando o texto a gente pode pensar ou ver as ideias que a gente não tinha colocado naquele texto. De repente, na hora, no dia que eu tava fazendo, eu não me lembrei daquilo, por exemplo. Ah! eu não lembrei que eu podia fazer daquele jeito, então, não pensei que podia seguir esse caminho. [...] quando tu deixa esse texto descansando e daí tu para e pensa "pô eu podia ter feito de tal jeito, né?; podia ter escrito assim, podia ter escrito de tal forma. Então é bom por isso. A gente esfria a cabeça, a gente sai da frente né?, do texto e aí quando a gente volta, a gente volta mais revigorada para continuar escrevendo (MARGARIDA - Entrevista pós-intervenção, grifos nossos).
\end{abstract}

Esse depoimento da acadêmica reforça a ideia que discutimos anteriormente acerca da tomada de consciência sobre as demandas da escrita, que se desenvolveram no decorrer da intervenção, agora focando na importância da revisão para detectar os problemas que seus textos apresentavam. Essa percepção reforça nossa pressuposição de que ela compreendeu que redigir um texto não é uma ação simples de pôr letras no papel, mas uma tarefa que envolve várias habilidades, como análise, reflexão, revisão e reescrita. Portanto, parece-nos que tomou consciência desses aspectos para a produção de um tex to claro e coeso.

Cabe ressaltar que, de acordo com nossa compreensão, o fato de a estudante não ter o hábito de revisar atentamente seus textos pode ser, igualmente, reflexo das práticas educativas que vivenciou com relação à produção de textos escritos, ao longo de sua escolarização, conforme expressou no questionário que aplicamos no primeiro encontro do semestre com o objetivo de conhecermos os sujeitos participantes deste estudo. Entendemos também que, possivelmente, a ausência de uma motivação pessoal para escrever, que ela parece revelar, mais uma vez, nesse segundo excerto, seja fruto do tipo de atividade escrita que lhe era solicitada durante sua formação. 
Rosa, outra das acadêmicas, ao ser questionada sobre sua atuação como alunaescritora, após participar da intervenção pedagógica, revelou que desenvolveu a tomada de consciência sobre a importância da coerência na construção da textualidade. A fala a seguir, oriunda da pergunta apresentada no início desta categoria, foi o que guiou essa interpretação.

Essa questão de colocar as palavras para dar coerência, o sentido na mesma frase ou um parágrafo a outro. Eu não analisava isso da forma como eu passei analisar depois da disciplina, com as palavras certas, que dão mais coerência à sequência que a gente quer falar e também a questão da gente sempre reler depois de um certo tempo que a gente escreve, dar um tempo, horas ou um dia pelo menos e voltar e ver o texto novamente que a gente consegue visualizar os erros mais fácil do que a gente ver na hora. [...]. Eu relia na hora e não dava um espaço de tempo. E aí que, normalmente, acontecia o maior número de erros. [...] depois que tu fazes [o texto] e deixas um tempo, tu consegues voltar numa escrita e ver o erro colocado de outra forma mais fácil. Ela [a disciplina] me ajudou a entender que eu preciso de um tempo maior pra visualizar o erro: quando a gente lê na hora, quando terminou de escrever, a gente, consegue ver o que a gente queria escrever e quando a gente dá um tempo, a gente realmente lê o que está escrito. [...] eu procuro ler as palavras, não ler o que eu queria escrever, que é o nosso hábito, [...], ler o que realmente está escrito; eu comecei a me disciplinar mais. Foi muito significativo pra mim aprender a ler o que a gente escreveu. (ROSA - Entrevista pós-intervenção, grifos nossos).

Rosa, ao avaliar sua atuação como escritora em relação ao início do semestre, expressou que aprendeu a analisar, de forma mais crítica, seus escritos. Em sua fala, percebemos, igualmente, indícios de que tomou consciência sobre as dificuldades que apresenta para redigir um texto. Ao dizer "com as palavras certas, que dão mais coerência à sequência que a gente quer falar", parece indicar que tomou consciência de que a coerência de um texto também está relacionada à precisão vocabular. É interessante comentar que a aluna se mostrou bastante surpresa quando explicamos, em sala de aula, que há verbos mais adequados do que outros para denominarmos as ações do autor do texto resumido. Esclarecemos à estudante que ao dizer "o autor argumenta" e o "autor exemplifica" estamos mencionando ações diferentes e que, portanto, necessitamos ter atenção ao verbo que traduza, o mais adequadamente possível, ao leitor, a ação expressa no texto original pelo seu autor.

Rosa, como Margarida, também não abordava a produção de texto como uma atividade processual. Perceber a importância do distanciamento temporal entre a escrita da primeira versão e a versão final foi muito significativo para ela, conforme expressou na entrevista pós-intervenção. As duas estudantes compreenderam que esse distanciamento é necessário para que possam refletir sobre suas próprias escritas e, sobretudo, encontrar alternativas à resolução dos problemas detectados no momento da revisão.

Podemos perceber por meio das verbalizações de Rosa, que ela, possivelmente, desenvolveu a tomada de consciência não só sobre a abordagem de texto como processo, mas também sobre a importância da revisão e da reescrita para a construção da textualidade. Nesse sentido, entendemos que a mediação e os processos interpsicológicos, vivenciados durante a intervenção, desempenharam função 
preponderante na tomada de consciência da estudante, corroborando as ideias de Vygotski $(2009$; 1995) acerca dos fatores que influenciam a tomada de consciência sobre nossas ações.

As verbalizações de Hortência também merecem nossa atenção, uma vez que contêm informações importantes sobre as aprendizagens que a acadêmica realizou ao participar da intervenção. A estudante, ao citar, no questionário pós-intervenção, essas aprendizagens, destacou "[...] a importância do homenzinho sentado no ombro [...]", revelando, em acordo com as ideias vygotskianas, o papel dos processos interpsicológicos e da mediação no desenvolvimento das habilidades de produção de textos escritos. Também, ao ser questionada sobre sua atuação como aluna-escritora, após ter participado da intervenção pedagógica, verbalizou que sua escrita estava

melhor, bem melhor.[...] [A revisão e a reescrita] Isso faz pensar e procurar a palavra certa para trabalhar aquilo. Eu penso que a reescrita, esse trabalho conjunto, [...] é que nem o indiozinho que aprende a fazer tudo com o pai: o pai vai pescar e o indiozinho vai para aprender e tu foste o pai do indiozinho: só se aprende vendo os outros. A situação de escrever e voltar nele é muito interessante. (HORTÊNCIA - Entrevista pós- intervenção, grifos nossos).

As verbalizações da estudante parecem revelar a tomada de consciência sobre a importância da revisão e da reescrita para a produção de textos escritos, especialmente quando expressa que essas ações fazem "pensar e procurar a palavra certa". Concordamos com Calkins (2002) quando defende que a revisão é essencial para o processo de escrita, porque nos ajuda a desenvolver o pensamento, justamente porque permite que revisitemos as ideias com as quais iniciamos nosso texto. A produção de um texto, dessa forma, é entendida como um processo de diálogo, de interação entre o escritor e seu escrito, no sentido bakhtiniano. Esse diálogo, a nosso ver, é imprescindível à construção da textualidade.

Hortência, ao verbalizar "a importância do homenzinho sentado no ombro" e "só se aprende vendo os outros", reforça a relevância da imitação (VYGOTSKI, 2009) no processo de aprendizagem e a importância de o professor atuar na $\mathrm{ZDP}^{3}$ de seus alunos, a fim de que possam internalizar o novo ou o conhecimento que ainda não dominam. $\mathrm{O}$ autor explica que o desenvolvimento decorrente da colaboração por meio da imitação é a fonte de onde surgem todas as propriedades especificamente humanas da consciência e esclarece que a imitação, se concebida em sentido amplo, é a maneira basilar pela qual ocorre a influência da aprendizagem sobre o desenvolvimento. Portanto, entendemos que o professor deve orientar a produção de textos, considerando a ZDP de seus estudantes, ou seja, observando quais elementos importantes à constituição do texto escrito ainda não estão amadurecidas naqueles estudantes, a fim de propiciar a eles modelos e momentos de interação com seu escrito para que possam amadurecer esse conhecimento e atingir o nível de desenvolvimento real. Caso contrário, conforme explica Vygotski (2000), o "ensino seria totalmente desnecessário se pudesse utilizar apenas o que já está maduro no desenvolvimento, se ele mesmo não fosse fonte de desenvolvimento e surgimento do novo" (VYGOTSKI, 2000, p.334).

${ }^{3}$ Zona de Desenvolvimento Proximal 
Magnólia expressou, no segundo questionário, que "penso que eu não avaliava o que eu estava escrevendo", permitindo-nos pressupor que houve tomada de consciência acerca de seu desempenho como revisora de seus textos. Embora a estudante não tenha expressado claramente como realizava a avaliação de seus textos antes de participar da intervenção, suas verbalizações nos permitem inferir que, talvez, o ato de revisão fosse por ela compreendido como uma atividade centrada apenas nos aspectos superficiais do texto.

No questionário que aplicamos no primeiro encontro do semestre com o objetivo de descrever os sujeitos participantes deste estudo, conforme já fizemos menção, as cinco acadêmicas verbalizaram que tinham o hábito de revisar seus textos. Todavia, podemos perceber, por meio das respostas dadas que entendiam a revisão e a reescrita como uma espécie de "operação de limpeza" superficial do texto, como denomina Jesus (2004).

Mediante algumas verbalizações que ilustraram a categoria que mencionamos no início desta análise, parece ficar clara a importância da função mediadora do professor, da revisão e da reescrita para a aprendizagem relativa à produção do texto escrito.

Compartilhamos das ideias de Assis e Mata (2005) quando defendem que o processo de apropriação da escrita no contexto acadêmico (ou em outro contexto) pressupõe o desenvolvimento da capacidade do estudante de avaliar sua produção durante e após o seu término, observando em que medida as ações de textualização empreendidas permitiram a concretização de seu projeto de dizer. Assim, tomando como base as ideias de Bakhtin (2006) e Vygotski (2009), compreendemos que, para ocorrer o desenvolvimento da capacidade de o estudante avaliar o que escreve, é necessário propiciar a ele práticas específicas e sistemáticas de escrita, revisão e reescrita, mediadas pelos conceitos científicos relativos ao assunto e por interações sociais. Acreditamos que somente mediante uma relação interlocutiva com seu texto, no interior de uma atividade social, o sujeito será capaz de desenvolver a capacidade de avaliar a qualidade dos textos que redige.

Assim, partindo das verbalizações das estudantes, podemos concluir que houve o desenvolvimento da tomada de consciência acerca de vários aspectos necessários à produção do texto escrito. Violeta, por exemplo, foi uma das estudantes que revelou o grau mais elevado de tomada de consciência sobre alguns dos problemas que suas produções escritas apresentavam. Já as outras acadêmicas (Margarida, Hortência, Rosa e Magnólia) relataram terem desenvolvido a tomada de consciência sobre processos envolvidos na produção textual. Margarida e Rosa não mencionaram, explicitamente, se perceberam os problemas que seus escritos continham, mas seus depoimentos trazem indícios da tomada de consciência sobre a abordagem de texto como processo e sobre a importância da revisão e da reescrita como ações fundamentais para a construção da textualidade, aspectos de extrema relevância para qualificarem suas escritas e desenvolverem suas ações pedagógicas, como futuras educadoras. Hortência também pareceu revelar a tomada de consciência sobre a importância da revisão e da reescrita para a melhoria do texto, embora já tivesse o hábito de revisar seus escritos. Além disso, a aluna salientou importância do "trabalho conjunto", fazendo referência às atividades de revisão e reescrita orientadas pela professora-pesquisadora.

\section{4) Algumas Reflexões}


Pensamos ser plausível entender que as verbalizações das estudantes que participaram deste estudo ratificam as ideias de Bakhtin (2006) e Vygotski (1997; 2000; 2009) sobre a importância das interações sociais, mediadas pela palavra, para o desenvolvimento da consciência. Para ambos, é na linguagem que está a fonte do comportamento social e da consciência. Bakhtin (2006) defende que "a palavra é o modo mais puro e sensível de relação social" (BAKHTIN, 2006, p.36); a considera o primeiro meio de constituição da consciência. Também, para Vygotski (1997), a palavra constitui e modifica a consciência; ele afirma que a "fala é um correlato da consciência" (VYGOTSKI, 1997, p.128). Vygotski (2009) instituiu a palavra como elemento mediador entre os homens, afirmando que ela é um meio de compreensão mútua entre as pessoas ratificando a relevância da interação entre professor, aluno e texto no desenvolvimento da tomada de consciência acerca de aspectos que constituem o texto escrito.

Entendemos que o ensino da escrita necessita estar baseado por ações mediadas e orientadas no sentido de propiciar o desenvolvimento da tomada de consciência e, consequentemente, do controle dos elementos da textualidade. Como para os dois autores russos, igualmente para nós, é o processo de interação, mediado pelo outro e pela linguagem, que desencadeia a internalização do conhecimento, em especial, do conhecimento necessário ao desenvolvimento da tomada de consciência e da capacidade de controle sobre as habilidades que permeiam o texto escrito.

O processo de mediação por meio da linguagem ocorrido no trabalho conjunto, desenvolvido durante a intervenção, parece ter sido o principal fator que contribuiu para o desenvolvimento da tomada de consciência das acadêmicas sobre as demandas relacionadas ao processo de escrever e das dificuldades que suas próprias escritas apresentavam. Shotter (2006, p. 16), com base na perspectiva histórico-cultural ${ }^{4}$ argumenta que "é por meio de palavras, de enunciações dos outros que agimos de maneira voluntária, consciente, passando a ser responsáveis ou a 'responder' por nossa própria conduta", confirmando que a tomada de consciência sobre nossos atos é um fato social, que provém das relações que estabelecemos com o meio em que estamos inseridos. Portanto, entendemos que é a experiência social mediada que determina a consciência, conforme explana Vygotski (1997) e Bakhtin (2006).

\section{5) Referências}

AGUIAR, Wanda; OZELLA, Sergio. Núcleos de significação como instrumento para apreensão da constituição dos sentidos. Psicologia, ciência e profisssão, 26 (2), 2006.

ASSIS, Juliana; MATA, Maria Aparecida da. A escrita de resumos na formação inicial do professor de Língua Portuguesa: movimento de aprendizagem no espaço de sala de aula. In: KLEIMAN, Ângela B. e Matêncio, Maria de Lourdes M. Letramento e formação de professor: práticas discursivas, representações e construção do saber.

\footnotetext{
${ }^{4}$ De acordo com a concepção vygotskiana, a abordagem histórico-cultural constitui um método da ciência psicológica que considera o desenvolvimento do ser humano como resultado de um movimento dialético, estabelecido entre os contextos histórico, social e cultural nos quais o ser humano está inserido.
} 
Campinas: Mercado de Letras, 2005, p. 181-202.

BAKHTIN, Mikhail. Marxismo e Filosofia da Linguagem. São Paulo: Hucitec, 2006.

CALKINS, Lucy. A Arte de Ensinar a Escrever: o desenvolvimento do discurso escrito. Porto Alegre: Artes Médicas, 2002.

DAMIANI. Magda (et al.). Diagnóstico e análise dos problemas da escrita acadêmica. Linguagem \& Ensino, Pelotas, V.14, N.1, p. 455-478, jul/dez 2011.

DAMIANI, Magda. Sobre pesquisas do tipo intervenção - painel: as pesquisas do tipo intervenção e sua importância para a produção de teoria educacional. In: XVI Encontro Nacional de Didática e Prática de Ensino, 2012, Campinas. Anais. Campinas: UNICAMP, p. 1-9.

DAMIANI, Magda (et al.). Discutindo pesquisas do tipo intervenção pedagógica. Cadernos de Educação. FaE/PPGE/UFPel.N ${ }^{\circ}$ 45. P. 57-67, 2013. Disponível em http://periodicos.ufpel.edu.br/ojs2/index.php/caduc/issue/current. Acesso em julho de 2014.

JESUS, Conceição de. Reescrevendo o texto: a higienização da escrita. In: CITELLI B.; GERALDI, J.W. Aprender e ensinar com textos de alunos. São Paulo: Cortez, 2004.

KRAMER, Sonia.; OSWALD, Maria Luiza. Leitura e escrita de professores em três escolas de formação. In: FREITAS, Maria Teresa.; COSTA, Sérgio Ricardo. Leitura e escrita na formação de professores. Juiz de Fora: UFJR, 2002.

MORAES, Roque. Uma tempestade de luz: a compreensão possibilitada pela análise textual discursiva. Ciência \& Educação, V.9, N. 2, p.191-211, 2003.

POUPART, Jean. A entrevista de tipo qualitativo: considerações epistemológicas, teóricas e metodológicas. In: A pesquisa qualitativa: enfoques epistemológicos e metodológicos. Petrópolis, RJ: Vozes, 2008.

SHOTTER, John. Conscientia, as witnessable knowing along with others. Theory \& Psychology, V.16, N.1, p.13-36, 2006.

STREET, Brian. Dimensões "escondidas" na escrita de artigos acadêmicos. Perspectiva, Florianópolis, V.28, N.2, p.541-567, jul./dez. 2010.

SZYMANSKY, Heloisa (org.). A Entrevista na Pesquisa em Educação: a prática reflexiva. Brasília: Liberlivros, 2004.

VIANNA, Heraldo. Pesquisa em educação: a observação. Brasília: Liber Livro Editora, 2007.

VYGOTSKI, Lev. Obras escogidas: Madrid: Visor Distribuciones, 1997. Tomo I.

VYGOTSKI, Lev. Obras escogidas. Madrid: Visor Distribuciones, 1995. Tomo III. 
VYGOTSKI, Lev. A formação social da mente: o desenvolvimento dos processos psicológicos superiores. São Paulo: Martins Fontes, 1998.

VYGOTSKY, Lev. A construção do pensamento e da linguagem. Tradução de Paulo Bezerra. São Paulo: Martins Fontes, 2000.

VYGOTSKY, Lev. A construção do pensamento e da linguagem. Tradução de Paulo Bezerra. São Paulo: Martins Fontes, 2009. 